\title{
PRESENT STATUS OF SWALLOWTAIL BUTTERFLIES IN GARBHANGA RESERVE FOREST, ASSAM, INDIA
}

\author{
K.K. Barua, D. Kakati and J. Kalita
}

Butterfly Research Centre, Department of Zoology, Guwahati University, Assam 781014, India.

\begin{abstract}
Garbhanga Reserve forest in Assam has a rich diversity of swallowtail butterflies with 29 species and subspecies belonging to eight genera. Habitat degradation caused by encroachment in fringe areas, illegal logging and stone quarrying is gradually posing a threat to the survival of these butterflies within the forest.
\end{abstract}

\section{Keywords}

Garbhanga, habitat, swallowtail butterflies, threat

The forests of Assam house a rich butterfly diversity. Evans (1932) described about 962 species and subspecies of butterflies belonging to the five families from the Assam region alone. Swallowtails belonging to family Papilionidae are one of the most spectacular insects that have drawn the attention of entomologists and naturalists. Globally 573 species of swallowtails have been identified so far and their distribution and status established (Collins \& Morris, 1985). There is a rich diversity of this predominantly forest-dwelling species in parts of East and Southeast Asia. Infact the International Union for Conservation of Nature and Natural Resources (IUCN) has identified northeastern India as one of the 'swallowtail-rich zones' under the Swallowtail Conservation Action Plan (1984).

According to earlier reports of Evans (1932) and Talbot (1939), about 62 species of swallowtails were described from the Assam region alone. However, most of these species are no longer common and the status of some species is either very rare or extinct. From the conservation point of view, swallowtails play a very important role in plant propagation through crosspollination. Moreover, a majority of medicinal plants are dependant on swallowtails for propagation. A wide variety of both flowering and non-flowering plants support the swallowtails as adult and larval food sources. These butterflies are very sensitive bio-indicators and have very specific habitat requirements. On account of their large size and brilliant colouration, these butterflies (live or dead) have great aesthetic and trade value.

The study was carried out to document the local swallowtail diversity in Garbhanga Reserve Forest $\left(25^{\circ} 55^{\prime}-25^{\circ} 05^{\prime} \mathrm{N} \& 91^{0} 37^{\prime}\right.$ $\left.91^{\circ} 49^{\prime} \mathrm{E}\right)$. The total forest cover is about $110 \mathrm{~km}^{2}$ and it is situated in an altitude of $100-200 \mathrm{~m}$. The topography mostly comprises of a hilly terrain with a perennial stream. The forest type is mostly mixed deciduous with a few scattered tropical evergreen pockets. The forest has diverse habitats ranging from an upland forest with a thick rainforest canopy to open forested areas with grassy patches and dense undergrowth vegetation along the stream.

\begin{abstract}
Methods
Surveys were carried out at different spots within the study area by point and line transect methods (Barhaum et al., 1980, 1981). The present survey was carried out from 2000 to 2002 during the pre-monsoon, monsoon and the post-monsoon seasons.
\end{abstract}

Butterflies were collected by chasing and netting as well as by bait trapping as mentioned by the Zoological Survey of India (1990). Surveys were mostly carried out during the first half of the day. The collected specimens were preserved and identified following ZSI (1990), Evans (1932), Talbot (1939), Wynter-Blyth (1957), Mani (1986) and Haribal (1992). One specimen representing each species and subspecies was preserved for future reference. A total of 70 individuals were collected and preserved. The collection included a male and a female of each species, dry and wet season forms and the polymorphic forms. To determine the status of different species within the study area, the number of individuals encountered along the line transect were counted (Barhaum et al., 1980, 1981). The available adult and larval host-plants were recorded in each transect. Host plants were identified by preparing herbarium following Dutta (1982) and Kanjilal (1936-1940).

\section{Results AND Discussion}

During the survey, 29 species and subspecies of swallowtail butterflies belonging to eight genera were identified in the study area, of which 10 were found to be very rare. They belonged to the genera Pachliopta, Lamproptera, Atrophaneura and Princeps. Out of the 29 species, nine were black-bodied swallowtails (Papilio and Princeps) and 11 belonged to the red-bodied group (Atrophaneura and Pachliopta). The blackbodied species were observed to prefer damp, shady places in the forest interior covered by canopy of tall trees and dense undergrowth near the water source. However species like the swordtails and zebras (Pathysa spp.) were found to particularly prefer open, grassy patches in forest fringes. The bluebottles and jays (Graphium spp.) as well as the swordtails (Pathysa spp.) and dragontails (Lamproptera spp.) were found to be particularly fond of mud puddling along the water stream. The natural preference of all the swallowtails for shady forest areas particularly during mid-day seemed to be controlled by the humidity of the specific area. Moreover, water sources encouraged adult butterflies to mud puddle in large congregations on the sandy patches along the stream.

The dominant larval food-plants of the black-bodied swallowtails belonged to the plant families Rutaceae, Annonaceae, Lauraceae and Magnoliaceae while the larvae of red-bodied swallowtails were found to prefer the plant family 


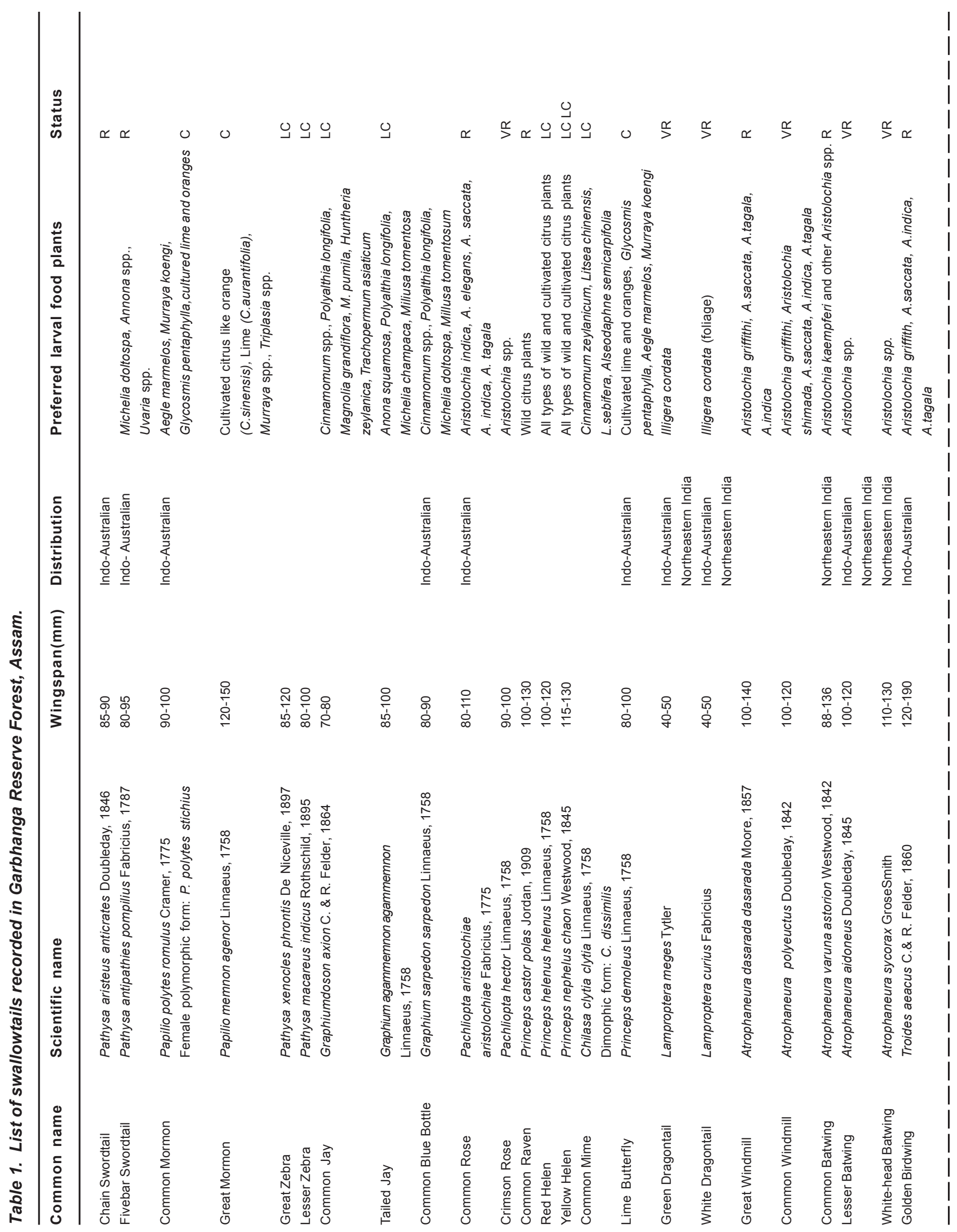


Aristolochiaceae that included Aristolochia tagala, A. indica and A. saccata. However, the present findings have revealed that the distribution of the Aristolochia species in the study area was very restricted. It was observed that the swallowtails visited the flowers of Lantana camara, Hibiscus rosasinensis, Ixora coccinea, Solanum nigrum, Tectona grandis, Saraca indica which are abundantly available within the study area.

The geographic location of any study area initiates the formation of a good habitat that can support rich butterfly diversity. As the study area harboured 29 species and subspecies of swallowtail butterflies, it can be presumed to have a good diversity of swallowtails, which may be attributed to Garbhanga being an ecotone transitional zone between the Meghalaya Plateau and Assam Valley. Although habitat conditions in Garbhanga are suitable for the propagation of swallowtail butterflies, increasing anthropogenic activities like stone quarrying, illegal tree-felling for fuel and timber and expanding human settlements in the fringe forest areas are slowly destroying the natural habitat of these butterflies leading to gradual decline in their population. To conserve all swallowtails, immediate measures to investigate the causes of habitat degradation both within the forest and adjoining areas must be taken to formulate suitable action plans to save the already dwindling population. Butterfly conservation awareness needs to be created amongst the masses particularly about swallowtail butterflies as they are habitat sensitive and they migrate away from a deteriorating habitat.

\section{REFERENCES}

Barhaum, K.P., D.R. Anderson and Z.L. Cauke (1980-1981). Estimation of Density from Line Transect Sampling of Biological Population. WILD. Monograph No. 72, 515pp.

Collins, N.M. and M.G. Morris (1985). Threatened Swallowtails of the World. The Red Data Book IUCN, Cambridge, U.K., 401pp.

Dutta, A.C. (1982). A Textbook of Botany. Oxford University Press, New Delhi.

Evans, W.H. (1932). The Identification of Indian Butterflies. Bombay Natural History Society, Bombay, 454pp.

Haribal, M. (1992). The Butterflies of Sikkim Himalaya and their Natural Histories. Sikkim Nature Conservation Foundation (SNCF), Gangtok, 217 pp.

Jairajpuri, M.S. (1990). Collection and Preservation of Animals. Zoological Survey of India, Calcutta.

Kanjilal, U.N. (1936-1940). Flora of Assam. Vol. 1-5, Government of Assam, Shillong.

Mani, M.S. (1986). Butterflies of the Himalaya. Oxford and IBH Co. Pvt. Ltd., New Delhi.

Talbot, G. (1939). The Fauna of British India including Ceylon and Burma: Butterflies. Vol. 1. Taylor and Francis, London.

Wynter-Blyth, M.A. (1957). Butterflies of the Indian Region. Bombay Natural History Society, Bombay, 523pp.+72pls. 